\title{
THE MOLECULAR INTERACTION AND ADMET PREDICTION OF MODIFIED JPH203 AS A POTENTIAL RADIOPHARMACEUTICAL KIT FOR MOLECULAR IMAGING OF CANCER: AN IN SILICO RESEARCH
}

\author{
HOLIS ABDUL HOLIK ${ }^{1}$, FAISAL MAULANA IBRAHIM ${ }^{1}$, ELISHA WIANATALIE ${ }^{1}$, ARIFUDIN ACHMAD ${ }^{2}$, AHMAD \\ FARIED ${ }^{3}$, ACHMAD HUSSEIN SUNDAWA KARTAMIHARDJA ${ }^{2}$
}

${ }^{1}$ Department of Pharmaceutical Analysis and Medicinal Chemistry, Faculty of Pharmacy/ Universitas Padjadjaran, Sumedang 45363, (West Java) Indonesia, ${ }^{2}$ Department of Nuclear Medicine, Faculty of Medicine/ Universitas Padjadjaran, Sumedang 45363, (West Java) Indonesia Email: holis@unpad.ac.id

Received: 22 Aug 2021, Revised and Accepted: 04 Oct 2021

ABSTRACT

Objective: In this study, various types of pharmacokinetic modifying linkers and chelators are combined with JPH203 to obtain the best-docked molecule for prospective radiopharmaceutical kits.

Methods: AutoDock 4.2.6 and AutoDockTools 1.5.6 programs was used to do the molecular docking simulation and ADMET prediction was done using VNN-ADMET to predict the pharmacokinetics and toxicity of the ligand.

Results: The result of this study showed that JPH203-linker K-NOTA has the best affinity with a docking score of about-10.7 kcal/mol and shows hydrogen interaction with Tyr259, which acts as key residue of the active site.

Conclusion: Based on the results, JPH203-linker K-NOTA has good potential as a radiopharmaceutical kit of cancer.

Keywords: JPH203, LAT-1, Molecular docking, ADMET, In silico

(C) 2021 The Authors. Published by Innovare Academic Sciences Pvt Ltd. This is an open access article under theCC BYlicense(https://creativecommons.org/licenses/by/4.0/) DOI: https://dx.doi.org/10.22159/ijap.2021.v13s4.43860 Journal homepage: https://innovareacademics.in/journals/index.php/ijap

\section{INTRODUCTION}

Cancer is a condition of abnormal cellular growth and proliferation. The cancer cells invade the surrounding tissue and can metastasize to other parts of the body. Currently, cancer is the second leading cause of death in the world (18.1 million cases of cancer in the world and 9.6 million cases of cancer deaths). Globally, one in six deaths is caused by cancer and $70 \%$ of cancer deaths occur in middle to low-income country [1].

Early detection and treatment of cancer is a big challenge. Recently, the cancer treatment paradigm has shifted towards personalized medicine with the discovery of targeted drugs, where a variety of new targeted drugs were developed clinically, but this has not made cancer treatment fulfill the expected pharmacological effect due to the heterogeneity of biological markers. These biomarkers are ideal drug targets in the future [2,3]. Much attention has been pointed to the target molecules that are suitable for cancer diagnosis and therapy, one of these molecules is LAT-1 $[4,5]$.

LAT-1 can distribute eight of the nine essential amino acids to certain body areas such as the placenta and blood-brain barrier so that LAT- 1 is said to be one of the main proteins in cell growth and development [6]. In addition, LAT-1 has overexpression and is highly selective against cancer cells, but its distribution is limited to normal cells [7]. The overexpression of LAT-1 in cancer cells and its ability to deliver substrates makes LAT-1 become a promising target for therapy and diagnostic (theranostic) molecules (fig. 1) [8,9].

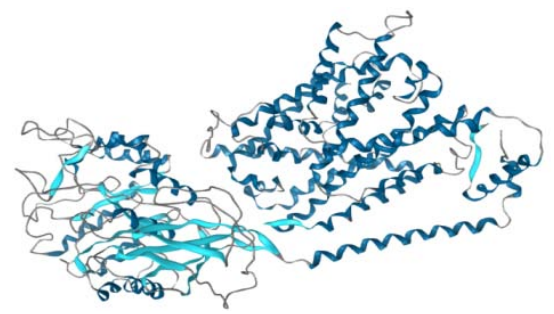

Fig. 1: The structure of large amino acid transporter type-1 (LAT-1) complexes with 4F2Hc [9]
Various compounds that have inhibitory activity on LAT-1 (e. g. JPH203), has a function as a tyrosine analog that can bind to LATsubstrates and showed a selective inhibiting effect on LAT-1 based on its in vitro and in vivo assays in mice with HT-29 tumors (colon cancer). JPH203 was also effective to inhibit various types of cancer [6]. So that JPH203 is promising to be a new anti-cancer agent [9].

Currently, a tool used in cancer diagnosis and therapy has been developed, namely theranostic radiopharmaceuticals, which are able to identify and treat various diseases (e. g. cancer, infectious diseases) [10]. The developments of theranostic radiopharmaceuticals need the ligands to bind with radionuclide and some require a bifunctional chelator to stabilize the metalligand complex [11]. To optimize the stability and activity of the radiopharmaceutical kit, we develop the various combination of JPH203 (carrier agent), pharmacokinetics modifier linker, and bifunctional chelator, which is docked to the LAT-1 structure through in silico studies. Nowadays, there has been no study that has been docked modified JPH203 with linker and chelator against LAT1 in the development of radiopharmaceutical kit formulation.

\section{MATERIALS AND METHODS}

\section{Hardware and software}

A personal computer with 6-cores 12-threads AMD Ryzen 5 2600, 3.4 GHz CPU with Radeon RX 570 GPU and 16 GB RAM was employed and equipped with the following software for in silico studies:

1. The ChemOffice 2010 and ChemDraw Ultra 12.0 software (PerkinElmer Inc., downloaded from http://www.cambridgesoft.com) for drawing 2D structures and convert them into 3D structures,

2. AutoDock 4.2.6 and AutoDockTools 1.5.6 programs (The Scripps Research Institute, downloaded from http://www.autodock.scripps.edu) for molecular docking simulations,

3. BIOVIA Discovery Studio 2017 R2 Client (Dassault Systèmes, downloaded from http://www.accelrys.com/) for visualization of PDB complex, the bond between ligands and receptors, geometry optimization, and overlays during the validation process, 
4. VNN-ADMET to predict the pharmacokinetics and toxicity of radiopharmaceutical kits.

\section{Designing radiopharmaceutical structures}

The 3D structure of the LAT-1 was downloaded from Protein Data Bank (PDB) (http://www.rscb.org, PDB ID: 6IRT). As a result of electron microscopy, LAT-1 (6IRT) was complexed with BCH molecules. The separation was performed using the BIOVIA Discovery Studio 2017 R2 Client. The 3D structure of the ligands (Radiopharmaceutical Kits, JPH203 Based) was drawn and has been optimized using ChemOffice 2010, and ChemDraw Ultra 12.0 (table S1, Supplementary Data).

\section{Validation of docking method}

The validation of molecular docking was conducted through a "redocking" procedure of the native ligand of 6IRT to its active site. The procedure is valid if the root mean square deviation (RMSD) $<2.0 \AA$ $[12,13]$. The results of validation process is shown in table 1 .

\section{Molecular docking simulation}

LAT-1 and all ligands were docked using AutoDock 4.2.6 and AutoDockTools 1.5 .6 programs. Ligands with the lowest bond energy $(\Delta G)$ to 6 IRT were selected and each interaction was further characterized by Biovia Discovery Studio. The ligands used were the modified structure of JPH203 with linkers and chelators that were used to bind radionuclides to form a complex.

\section{ADMET prediction}

ADME and Toxicity predictions including drug-induced liver injury (DILI), cytotoxicity (HepG2), HLM, CYPs inhibitor, blood-brain barrier (BBB), p-gp inhibitor, p-gp substrate, cardiotoxicity, mitochondrial toxicity (MMP), Mutagenicity (AMES), maximum recommended therapeutic dose (MRTD) and significant descriptors of drug properties such as mutagenicity, toxicological dosage level for different tissues, and pharmacologically relevant properties of the compounds were predicted using web applications at vNN-ADMET (https://vnnadmet.bhsai.org/ vnnadmet/login.xhtml) by Schyman [14].

\section{RESULTS}

Table 1: Validation of docking method to the LAT-1

\begin{tabular}{lllll}
\hline Native ligand & Grid address $(\mathbf{x}, \mathbf{y}, \mathbf{z})$ & $\mathbf{\Delta G}(\mathbf{k c a l} / \mathbf{m o l})$ & RMSD $(\AA)$ & Interaction (H-Bond) \\
\hline N1 & $(155.98,120.75,190.07)$ & -3.11 & 4.832 & Arg452, Asn507, Ser505, Ala448, Leu520, Ser519, Gln 513, Met508 \\
N2 & $(147.38,154.55,206.56)$ & -4.52 & 4.608 & Ser383, Asp385, Gln388, Asn382, Ser404 \\
N3 & $(143.61,177.30,186.04)$ & -3.99 & 3.878 & Asn366, Ser395, Ser359, Glu363 \\
N4 & $(120.89,152.65,188.29)$ & -3.24 & 4.479 & Asn425 \\
N5 & $(146.32,143.11,134.34)$ & -5.25 & 1.827 & Gly67, Ser66, Ile64, Tyr289, Gly255, Phe252 \\
N6 & $(123.02,140.49,124.78)$ & -3.37 & 3.505 & - \\
N7 & $(125.27,129.23,119.46)$ & -1.85 & 3.277 & Cys496 \\
\hline
\end{tabular}
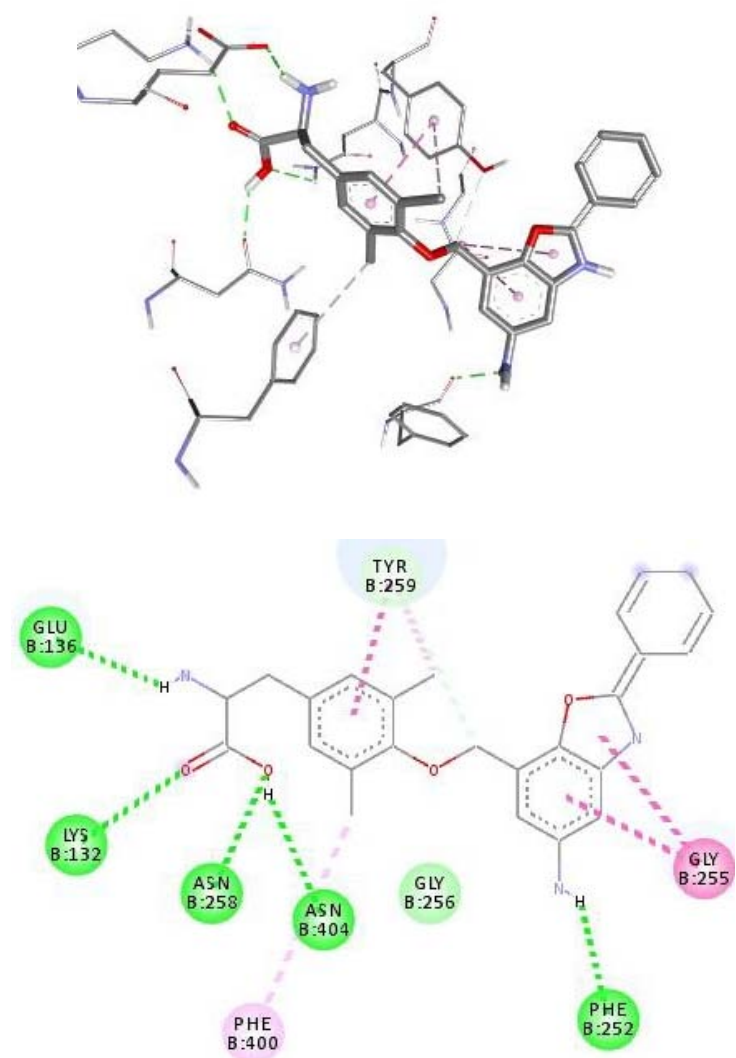

(a)
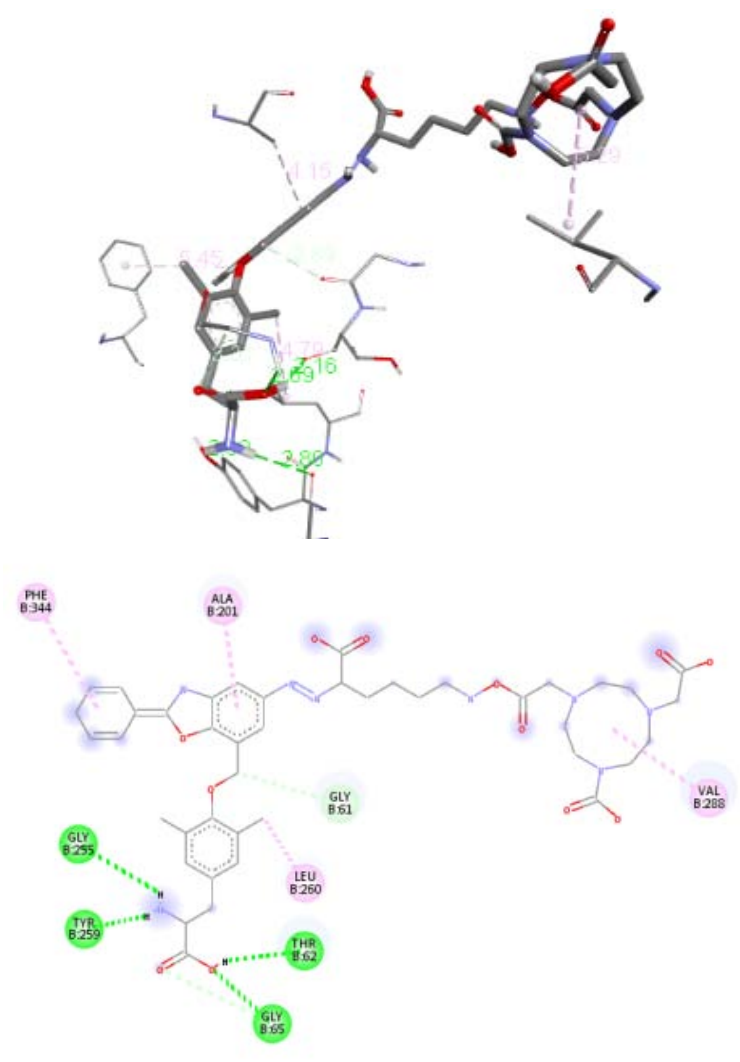

(b)

Fig. 2: Visualization of the docked ligand with LAT-1 (a) Interaction of LAT-1 amino acid with JPH203 as a lead compound (b) Interaction of LAT-1 amino acid with JPH203-K linker-NOTA as the best-docked molecule 
Table 2: Molecular docking parameters of JPH203 and Its derivatives

\begin{tabular}{|c|c|c|c|c|c|}
\hline \multicolumn{3}{|l|}{ Ligand } & \multirow{2}{*}{$\begin{array}{l}\Delta G \\
\text { (kcal/mol) }\end{array}$} & \multirow[t]{2}{*}{$\mathbf{K I}(\mu \mathrm{M})$} & \multirow[t]{2}{*}{ Hydrogen interaction } \\
\hline JPH203 & Linker & Chelator & & & \\
\hline & - & - & -9.4 & $1.2 \mathrm{E}-07$ & Glu136, Lys132, Asn258, Asn404, Phe252 \\
\hline & E linker & NOTA & -10.2 & $3.3 \mathrm{E}-08$ & Asp198, Gly61, Ser66, Tyr259, \\
\hline & & DOTA & -10 & 4.6E-08 & Phe344, Gln197 \\
\hline & & TETA & -10.6 & $1.7 \mathrm{E}-08$ & Thr194, Gln197, Gly61, Gly65, Gly255, Gly67, Ser66 \\
\hline & & CTPA & -10 & $4.6 \mathrm{E}-08$ & Gly255, Ser338, Gln197, Thr62 \\
\hline & & H2CB-D02A & -10.2 & 3.3E-08 & Phe344, Leu343 \\
\hline & & H2CB-TE2A & -9 & $2.5 \mathrm{E}-07$ & Thr154, Thr62, Lys204, Gly61, Gln197 \\
\hline & K linker & NOTA & -10.7 & $1.4 \mathrm{E}-08$ & Thr62, Gly65, Tyr259, Gly255 \\
\hline & & DOTA & -10.1 & $3.9 \mathrm{E}-08$ & Ala202, Ile63, Thr62 \\
\hline & & TETA & -9.2 & $1.8 \mathrm{E}-07$ & Phe344, Thr194, Gln197 \\
\hline & & CTPA & -9.5 & $1.1 \mathrm{E}-07$ & Gly337, Thr62, Gly61 \\
\hline & & H2CB-D02A & -9.2 & $1.8 \mathrm{E}-07$ & Thr62, Lys204 \\
\hline & & H2CB-TE2A & -10.5 & $2 \mathrm{E}-08$ & Gly65, Gly255 \\
\hline & PEG4 linker & NOTA & -9.8 & $6.4 \mathrm{E}-08$ & Gln197, Thr62 \\
\hline & & DOTA & -8.8 & $3.5 \mathrm{E}-07$ & Asp198 \\
\hline & & TETA & -9.7 & 7.6E-08 & Thr62, Gln197 \\
\hline & & CTPA & -9.6 & $9 \mathrm{E}-08$ & Leu343 \\
\hline & & H2CB-D02A & -10.1 & $3.9 \mathrm{E}-08$ & Leu205, Gly337, Gln197, Thr62 \\
\hline & & H2CB-TE2A & -10 & $4.6 \mathrm{E}-08$ & Gly255, Gln197 \\
\hline
\end{tabular}

Table 3: ADMET prediction of JPH203 and its derivatives

\begin{tabular}{|c|c|c|c|c|c|c|c|c|c|c|c|c|c|c|c|}
\hline Query & DILI & $\begin{array}{l}\text { Hepar } \\
\text { Cyto- } \\
\text { toxicity }\end{array}$ & HLM & $\begin{array}{l}\text { Cyp1A2 } \\
\text { Inh }\end{array}$ & $\begin{array}{l}\text { Cyp3A4 } \\
\text { Inh }\end{array}$ & $\begin{array}{l}\text { Cyp2D6 } \\
\text { Inh }\end{array}$ & $\begin{array}{l}\text { Cyp2C9 } \\
\text { Inh }\end{array}$ & $\begin{array}{l}\text { Cyp2C19 } \\
\text { Inh }\end{array}$ & BBB & $\begin{array}{l}\text { P- } \\
\text { gp } \\
\text { Inh } \\
\end{array}$ & $\begin{array}{l}\text { P-gp } \\
\text { Subs }\end{array}$ & $\begin{array}{l}\text { hERG } \\
\text { Blocker }\end{array}$ & MMP & AMES & $\begin{array}{l}\text { MRTD } \\
\text { (mg/day) }\end{array}$ \\
\hline JPH203 & Yes & No & Yes & No & No & No & No & No & No & Yes & Yes & No & No & No & 293 \\
\hline $\begin{array}{l}\text { JPH203- } \\
\text { E-CTPA }\end{array}$ & Yes & No & Yes & No & No & No & No & No & Yes & Yes & Yes & Yes & No & No & 324 \\
\hline $\begin{array}{l}\text { JPH203- } \\
\text { E-DOTA }\end{array}$ & Yes & No & Yes & No & No & No & No & No & No & No & Yes & Yes & No & No & 346 \\
\hline $\begin{array}{l}\text { JPH203- } \\
\text { E-D02A }\end{array}$ & Yes & No & Yes & No & No & No & No & No & No & Yes & Yes & No & No & No & 347 \\
\hline $\begin{array}{l}\text { JPH203- } \\
\text { E-TE2A }\end{array}$ & Yes & No & Yes & No & No & No & No & No & No & Yes & Yes & No & No & No & 344 \\
\hline $\begin{array}{l}\text { JPH203- } \\
\text { E-NOTA }\end{array}$ & Yes & No & Yes & No & No & No & No & No & No & Yes & Yes & Yes & No & No & 319 \\
\hline $\begin{array}{l}\text { JPH203- } \\
\text { E-TETA }\end{array}$ & Yes & No & Yes & No & No & No & No & No & No & Yes & Yes & Yes & No & No & 327 \\
\hline $\begin{array}{l}\text { JPH203- } \\
\text { K-CTPA }\end{array}$ & Yes & No & Yes & No & No & No & No & No & Yes & No & Yes & Yes & No & No & 314 \\
\hline $\begin{array}{l}\text { JPH203- } \\
\text { K-DOTA }\end{array}$ & No & No & Yes & No & No & No & No & No & No & No & Yes & Yes & No & No & 393 \\
\hline $\begin{array}{l}\text { JPH203- } \\
\text { K-DO2A }\end{array}$ & Yes & No & Yes & No & No & No & No & No & No & Yes & Yes & No & No & No & 336 \\
\hline $\begin{array}{l}\text { JPH203- } \\
\text { K-TE2A }\end{array}$ & Yes & No & Yes & No & No & No & No & No & No & Yes & Yes & No & No & No & 335 \\
\hline $\begin{array}{l}\text { JPH203- } \\
\text { K-NOTA }\end{array}$ & Yes & No & Yes & No & No & No & No & No & No & Yes & Yes & Yes & No & No & 310 \\
\hline $\begin{array}{l}\text { JPH203- } \\
\text { K-TETA }\end{array}$ & Yes & No & Yes & No & No & No & No & No & No & Yes & Yes & Yes & No & No & 329 \\
\hline $\begin{array}{l}\text { JPH203- } \\
\text { PEG4- } \\
\text { CTPA }\end{array}$ & Yes & No & Yes & No & No & No & No & No & No & Yes & Yes & Yes & No & No & 385 \\
\hline $\begin{array}{l}\text { JPH203- } \\
\text { PEG4- } \\
\text { DOTA }\end{array}$ & Yes & No & Yes & No & No & No & No & No & No & Yes & Yes & Yes & No & No & 414 \\
\hline $\begin{array}{l}\text { JPH203- } \\
\text { PEG4- } \\
\text { DO2A }\end{array}$ & Yes & No & Yes & No & No & No & No & No & No & Yes & Yes & No & No & No & 424 \\
\hline $\begin{array}{l}\text { JPH203- } \\
\text { PEG4- } \\
\text { TE2A }\end{array}$ & Yes & No & Yes & No & No & No & No & No & No & Yes & Yes & No & No & No & 418 \\
\hline $\begin{array}{l}\text { JPH203- } \\
\text { PEG4- } \\
\text { NOTA }\end{array}$ & Yes & No & Yes & No & No & No & No & No & No & Yes & Yes & Yes & No & No & 391 \\
\hline $\begin{array}{l}\text { JPH203- } \\
\text { PEG4- } \\
\text { TETA }\end{array}$ & Yes & No & No & No & No & No & No & No & No & Yes & Yes & Yes & No & No & 408 \\
\hline
\end{tabular}

\section{DISCUSSION}

The electron microscopy structure of LAT-1 (in complex with BCH inhibitor and 4F2Hc, PDB ID: 6IRT) was selected for molecular docking studies of JPH203 and its derivatives. The specifications of
6IRT are the experimental resolution (3.5 ̊), and it is expressed by Homo sapiens.

$\mathrm{BCH}$ and 4F2Hc that were contained in the selected microscopy structure of LAT- 1 must be extracted from the LAT- 1 structure and 
re-docked to verify that the molecular docking software can reproduce the agonist conformation of the native ligand (N3). The result is valid if the obtained Root Mean Square Deviation (RMSD) value is $\leq 2.0 \AA$ [7]. The best-docked N3 conformation showed an RMSD of $1.827 \AA$ compared to the previous pose (table 1 ).

The modified structure of JPH203 and its derivatives are shown in table S1 (Supplementary Data). Modified structures of JPH203 are obtained from the combination of various PKM (Pharmacokinetics Modifying Linkers) and BFCA (Bifunctional Chelating Agent). The 2D structure of ligands was drawn with ChemDraw Ultra 12.0 and converted to $3 \mathrm{D}$ by Chem3D Ultra 12.0. The predominant conformational ligand structures (the correct geometry and conformation) of each modified JPH203 has been determined by energy minimization calculations using the Austin Model (AM1) semi-empirical method.

JPH203 and its derivatives have a $\Delta \mathrm{G}$ value greater than-5.5 $\mathrm{kcal} / \mathrm{mol}$. However, only two molecules of JPH203 derivatives that can bind with key amino acid residue (gating residue) that is JPH203-Linker E-NOTA and JPH203-Linker K-NOTA by interacting with Tyr259 through hydrogen bond interaction with $\mathrm{H}$-amine of JPH203 in JPH203-K-NOTA structure. The results showed in table 2.

Table 1 shows molecular docking parameters of 18 ligands and JPH203 as the lead compound. JPH203-K linker-NOTA is performed as the best-docked molecule $(\Delta \mathrm{G}=-10.7 \mathrm{kcal} / \mathrm{mol})$ and it can bind Tyr259 through hydrogen bond (fig. 2), which acts as the gating residue of LAT-1 transport activity.

Targeting the key residues (gating residues) in the active site of LAT-1 is the main inhibition strategy to inactivate the LAT-1 proteolytic function. The gating residues of transport activity of LAT-1 is presented by Tyr117, Phe252, Trp257, Asn258, Tyr259 and Arg348 [15]. The hydrogen bonds between protein side chains and drug are fundamental for inhibition and stability, thus play a significant role in drug-receptor interaction. The distance between the hydrogen-bond donor and acceptor (the shorter, the stronger) determine the strength of a hydrogen bond [16]. The result obtained from the docked modified structures of JPH203, indicates that all of our molecules meet the molecular docking parameter (minus value showed a spontaneous complection between the ligands and its target). However, only two molecules of JPH203 derivatives that can bind with key amino acid residue (gating residue) that is JPH203-Linker E-NOTA and JPH203Linker K-NOTA by interacting with Tyr259 through Hydrogen Bond Interaction with H-amine of JPH203 in JPH203-K-NOTA structure. The details of the result can be seen in table 2 .

JPH203-K linker-NOTA (fig. 2) was identified as the best-docked molecule $(\Delta \mathrm{G}=-10.7 \mathrm{kcal} / \mathrm{mol})$ and it can bind Tyr259 through hydrogen bond, which acts as the gating residue of LAT-1 transport activity. Based on the previous research, Tyr259 inhibition decreases $80 \%$ transport activity of LAT-1 [13]. Therefore, the molecular interaction of JPH203-K linker-NOTA is promising for developing new radiopharmaceutical kits, while the rest of the molecules are excluded. Besides that, JPH203-K linker-NOTA showed a better inhibition constant $\left(\mathrm{Ki}=1.4 \times 10^{-8} \mu \mathrm{M}\right)$ than its lead compound $\left(\mathrm{Ki}=1.2 \times 10^{-7} \mu \mathrm{M}\right)$. These results showed that molecular docking parameters of JPH203-K linker-NOTA have a better docking parameter than the lead compound.

Table 3 shows the ADMET Prediction of the modified structure of JPH203. Most of all the molecules have good distribution and metabolism parameters. JPH203-K linker-NOTA does not penetrate BBB and is not a CYP inhibitor, has a much saver MRTD compared to other compounds ( $310 \mathrm{mg} /$ day), but the compound has relatively unsafe toxicity parameters, especially hepatotoxicity (DILI parameters) and has cardiotoxic effect.

Table 3 shows results that JPH203-E-NOTA and JPH203-K-NOTA show better ADMET parameters (yellowed) than JPH203 itself as lead compound and DOTATE (the comparison compound, FDA approved). Based on the results of ADMET predictions, the JPH203$\mathrm{K}$ linker-NOTA compound has a good distribution parameter as well as drug metabolism where the compound does not penetrate BBB and is not a CYP inhibitor. This suggests that this radiopharmaceutical kit candidate will not have CNS effects in the brain and will not experience drug damage before the drug reaches the receptors. However, the JPH230-K linker-NOTA compound has relatively unsafe toxicity parameters, especially hepatotoxicity (seen in DILI parameters), and has a cardiotoxic effect. Fortunately, these toxicity parameters can be negligible because radiopharmaceutical kits are generally required in very small quantities so that the toxic effects of the drug can be avoided. Other toxicity parameters possessed by these compounds are in the safe ranges, namely mutagenicity (AMES) and mitochondrial toxicity. The JPH203-K linker-NOTA compound also has a much safer MRTD compared to other compounds $(310 \mathrm{mg} / \mathrm{day})$; this shows that this radiopharmaceutical kit has the potential to avoid toxic effects resulting from the use of drugs in large quantities much smaller.

\section{CONCLUSION}

Molecular docking and ADMET structure-based prediction studies revealed JPH203-K linker-NOTA met the criteria as candidates of LAT-1 carrier drug for radiopharmaceutical kit in cancer therapy and or diagnostic.

\section{ACKNOWLEDGEMENT}

The Author Thankful to the Directorate of Research and Community Service, Universitas Padjadjaran.

\section{FUNDING}

This research was funded through "Hibah Penelitian Dasar Unggulan Perguruan Tinggi issued (No.1827/UN6.3.1/lT/2020) from The Directorate General of Higher Education, The Ministry of Education, Research, and Technology of The Republic of Indonesia.

\section{AUTHORS CONTRIBUTIONS}

All the authors contributed equally.

\section{CONFLICT OF INTERESTS}

\section{Declared none}

\section{REFERENCES}

1. Noncommunicable diseases. Available from: https://www.who.int/news-room/fact-

sheets/detail/noncommunicable-diseases. [Last accessed on 20 Jul 2020].

2. Blackadar CB. Historical review of the causes of cancer. World J Clin Oncol. 2016;7(1):54-86. doi: 10.5306/wjco.v7.i1.54, PMID 26862491.

3. Bright CJ, Reulen RC, Winter DL, Stark DP, McCabe MG, Edgar $\mathrm{AB}$, Frobisher C, Hawkins MM. Risk of subsequent primary neoplasms in survivors of adolescent and young adult cancer (Teenage and Young Adult Cancer Survivor Study): a population-based, cohort study. Lancet Oncol. 2019;20(4):53145. doi: 10.1016/S1470-2045(18)30903-3, PMID 30797674.

4. Bray F, Ferlay J, Soerjomataram I, Siegel RL, Torre LA, Jemal A. Global cancer statistics 2018: GLOBOCAN estimates of incidence and mortality worldwide for 36 cancers in 185 countries. CA Cancer J Clin. 2018;68(6):394-424. doi: 10.3322/caac.21492, PMID 30207593.

5. Choi DW, Kim DK, Kanai Y, Wempe MF, Endou H, Kim JK. JPH203, a selective L-type amino acid transporter 1 inhibitor, induces mitochondria-dependent apoptosis in Saos2 human osteosarcoma cells. Korean J Physiol Pharmacol. 2017;21(6):599-607. doi: 10.4196/kjpp.2017.21.6.599, PMID 29200902.

6. Scalise M, Galluccio M, Console L, Pochini L, Indiveri C. The human SLC7A5 (LAT1): the intriguing histidine/large neutral amino acid transporter and its relevance to human health. Front Chem. 2018;6:243. doi: 10.3389/fchem.2018.00243, PMID 29988369.

7. Achmad A, Lestari S, Holik HA, Rahayu D, Bashari MH, Faried A, Kartamihardja AHS. Highly specific l-type amino acid transporter 1 inhibition by JPH203 as a potential pan-cancer treatment. Processes. 2021;9(7):1170. doi: 10.3390/ pr9071170. 
8. Hayashi K, Jutabha P, Maeda S, Supak Y, Ouchi M, Endou H, Fujita T, Chida M, Anzai N. LAT1 acts as a crucial transporter of amino acids in human thymic carcinoma cells. J Pharmacol Sci. 2016 Nov;132(3):201-4. doi: 10.1016/j.jphs.2016.07.006, PMID 27567475.

9. Oda K, Hosoda N, Endo H, Saito K, Tsujihara K, Yamamura M, Sakata T, Anzai N, Wempe MF, Kanai Y, Endou H. L-type amino acid transporter 1 inhibitors inhibit tumor cell growth. Cancer Sci. 2010 Jan;101(1):173-9. doi: 10.1111/j.13497006.2009.01386.x, PMID 19900191.

10. Sarko D, Eisenhut M, Haberkorn U, Mier W. Bifunctional chelators in the design and application of radiopharmaceuticals for oncological diseases. Curr Med Chem. 2012;19(17):266788. doi: 10.2174/092986712800609751, PMID 22455579.

11. Liu S. Bifunctional coupling agents for radiolabeling of biomolecules and target-specific delivery of metallic radionuclides. Adv Drug Deliv Rev. 2008 Sep;60(12):1347-70. doi: 10.1016/j.addr.2008.04.006, PMID 18538888.

12. Ibrahim FM, Holik HA, Achmad A. In silico studies of amentoflavone and its derivatives against SARS-COV-2. Rasayan J Chem. 2021;14(3):1469-81.

13. Hidayat S, Ibrahim FM, Pratama KF, Muchtaridi M. The interaction of alpha-mangostin and its derivatives against main protease enzyme in COVID-19 using in silico methods. J Adv Pharm Technol Res. 2021;12(3):285-90.

14. Patrick S, Lui R, Valmik Desai AW. Illqvist, vNN web server for ADMET predictions. Front Pharmacol. 2017;8(889).

15. Yan R, Zhao X, Lei J, Zhou Q. Structure of the human LAT1-4F2hc heteromeric amino acid transporter complex. Nature. 2019;568(7750):127-30. doi: 10.1038/s41586-019-1011-z, PMID 30867591.

16. Jeffrey GA. An introduction to hydrogen bonding. England: Oxford University Press. England; 1997. 